\title{
PENGEMBANGAN PRODUKSI DAN PEMASARAN MADU WETAR
}

\section{PRODUCTION AND MARKETING DEVELOPMENT OF WETAR HONEY}

\author{
Mersiana Sahureka $^{1)}$;roice Siahaya ${ }^{2)}$; Wilma N.Imlabla ${ }^{3)}$ \\ .Jurusan Kehutanan, Fakultas Pertanian Universitas Pattimura, Kampus Poka Ambon, 97233. \\ E-mail : mersisahu@gmail.com \\ \begin{tabular}{|l|l}
\hline Diterima : 22 Agustus 2019 & Disetujui : 13 September 2019
\end{tabular}
}

\begin{abstract}
Abstrak
Tujuan dari penelitan ini adalah untuk mengetahui rantai pemasaran madu wetar dan factorfaktor yang mempengaruhi produksi dan pemasaran madu wetar. Metode penelitian yang digunkan yakni metosede deskrispi kualitatif sedangkan pengumpulan data yang dilakukan melalui wawancara dan FGD dengan kelompok usaha madu wetar dan juga melakukan uji laboratorium terhadap sampel madu wetar di Balai Pengawasan Obat dan Makanan (BPOM) Ambon untuk mendapatkan sertifikat. Dan hasil penelitian deskripsikan secara kuanlitatif maupun kuantitaf. Hasil yang dicapai dalam penelitian ini yakni usaha madu wetar memberikan hasil yang sangat besar bagi peningkatan ekonomi masyarakat jika ada upaya pengembangan baik dari segi produksi yakni mulai pengambilan sarang lebah hingga pengemasan. Sedangkan segi pemasaran yakni rantai pemasaran ,distibusi dan promosi perlu dikembangkan. Total peningkatan pendapatan respondens dari pengembangan madu wetar yakni Rp $50.000-\mathrm{Rp}$ 70.000 per $500 \mathrm{ml}$. Berdasarkan surat BPOM Ambon Nomor PM.02.04.1092.04 terhadap uji parameter madu untuk ukuran $500 \mathrm{ml}$ telah lulus uji/ memenuhi syarat untuk dikomsumsi.
\end{abstract}

Kata Kunci: Produksi, Pemasaran, Madu

\begin{abstract}
The purpose of this research is marketing of wetar honey in order to know the marketing chain of wetar honey and the factors that influence the production and marketing of wetar honey.The research method used is a qualitative description method and data collection were conducted through interviews and FGDs with farmers group of wetar honey and also conducted laboratory test of wetar honey sample at Ambon Food and Drug Administration (BPOM) to obtain certificate. The results of this research are quantitatively and qualitatively describe. The results achieved in this study wetar honey business provides a very large result for the improvement of the community economy if there is a development effort both in terms of production ie from honeycomb to packaging, as well as marketing terms which are marketing, distribution dan promosion developed.. Total respondent increase income from the development of wetar honey is Rp 50.000 - Rp $70.000 / 500 \mathrm{ml}$. Based on the letter from BPOM Ambon Number PM.02.04.1092.04 to the honey parameter test for $500 \mathrm{ml}$ size has passed the test / eligible for consumption.
\end{abstract}

Keywords: Production, Marketing, Honey 
PENDAHULUAN

Madu adalah cairan alami yang umumnya mempunyai rasa manis yang dihasilkan oleh lebah madu dari sari bunga tanaman (flora nektar) atau bagian lain dari tanaman (ekstrak flora nectar) atau ekskresi serangga (Gebremariam dalam Wulandari 2017). Madu mengandung banyak mineral seperti natrium, kalsium, magnesium, alumunium, besi, fosfor dan kalium. Vitaminvitamin yang terdapat dalam madu adalah thiamin (B1), riboflavin (B2), asam askorbat (C), piridoksin (B6), niasin, asam pantotenat, biotin, asam folat, dan vitamin K. Sedangkan enzim yang penting dalam madu adalah enzim diastase, invertase, glukosa oksidase, peroksidase, invertase, glukosa oksidase, peroksidase dan lipase. Selain itu unsur kandungan lain madu adalah memiliki zat antibiotic atau antibakteri ( Adji S dalam Wulandari 2007).

Madu asal pulau Wetar Kabupaten Maluku Barat Daya yang dikenal dengan nama Madu Wetar merupakan madu hutan diambil langsung dari hutan alam yakni dari sarang-sarang lebah yang ada pepohonan. Sarang-sarang lebah madu diambil oleh masyarakat dengan cara memanjat dan memotong sarang-sarang lebah kemudian memisahkan cairan madu dari lilinnya, dan mengisi dalam botol-botol kemasan. Kelompok usaha madu Sion merupakan salah satu kelompok masyarakat yang memanen dan menjual madu hutan.
Kegiatan produksi maupun pemasaran madu masih dilakukan secara sederahana dengan peralatan manual dan pemasaran dengan alur distribusi pendek yakni dari produsen ke konsumen akhir. Hal ini dikarenakan jauhnya jarak dam sulit'nya akses masyarakat ke ibu kota propinsi maupun ibu kota kabupaten yang harus menggunakan kapal perintis hingg berharihari perjalanan. Sehingga terkadang madu yang telah diambil dalam jumlah banyak hanya untuk di konsumsi sendiri ataupun diberikan sebagai ole-ole dan hanya sedikit saja yang bisa menempus pasar di ibu kota kabupaten maupun ibu kota propinsi.

Produk madu yang diproduksi oleh kelompok usaha Sion wetar belum dilengkapi dengan hasil uji laboratorium Balai Pengawasan Obat dan Makanan, izin pendirian usaha (PIRT) dan izin edar maupun izin merek. Hal ini turut mempengaruhi harga jual maupun daya beli konsumen untuk membeli madu wetar. Hal ini merupakan suatu kendala yang menyebabkan kegiatan produksi dan pemasaran madu tidak laris dan belum terkenal di pasaran. Dengan demikian perlunya upaya pengembangan produksi dan pemasaran madu wetar agar dapat meningkatkan nilai ekonominya. Adapun tujuan dari penelitian ini adalah mengetahui rantai pemasaran madu wetar, mengetahui faktor-faktor yang mempengaruhi produksi dan pemasaran madu wetar asal desa Hiay, dan mengetahui upaya pengembangan 
produksi dan pemasaran madu wetar untuk meningkatkan nilai poduksi

\section{METODOLOGI PENELITIAN}

Penelitian yang digunakan yakni metode deskripsi kualitatif dan pengumpulan data primer dan sekunder melalui wawancara dan FGD yakni kelompok usaha madu Wetar Sion maupun tokoh masyarakat desa Hiay. Selain itu dilakukan uji sampel madu hutan asal desa Hiay Wetar pada laboratorium Balai Pengawasan Obat dan Makanan (BPOM) Ambon.

\section{HASIL DAN PEMBAHASAN}

Aktifitas Masyarakat Desa Hiay dari Pengambilan Sarang Lebah Madu (Produksi)

Salah satu jenis lebah yang dapat menghasilkan madu hutan adalah jenis Apis dorsata yang lebih dikenal dengan lebah madu raksasa yang berhabitat di hutan. Oleh karena keterbatasan pengetahuan khususnya mengenai biologi lebah dan persyaratan mutu madu maka teknik pemungutan dilaksanakan oleh masyarakat desa Hiay masih sangat sederhana. Disamping itu di dalam pelaksanaannya sering dijumpai para petani madu membakar dan menghabiskan sisiran sarang, sehingga dapat mengganggu perkembangan populasi jenis lebah madu. Sarang lebah madu di desa Hiay memiliki keunikan tersendiri karena kebanyakan sarang lebah ini bergantungan di dahan dan ranting pohon yang rendah. Ada juga masyarakat yang mengambilnya dengan tidak perlu memanjat pohon karena letaknya yang tidak terlalu tinggi.
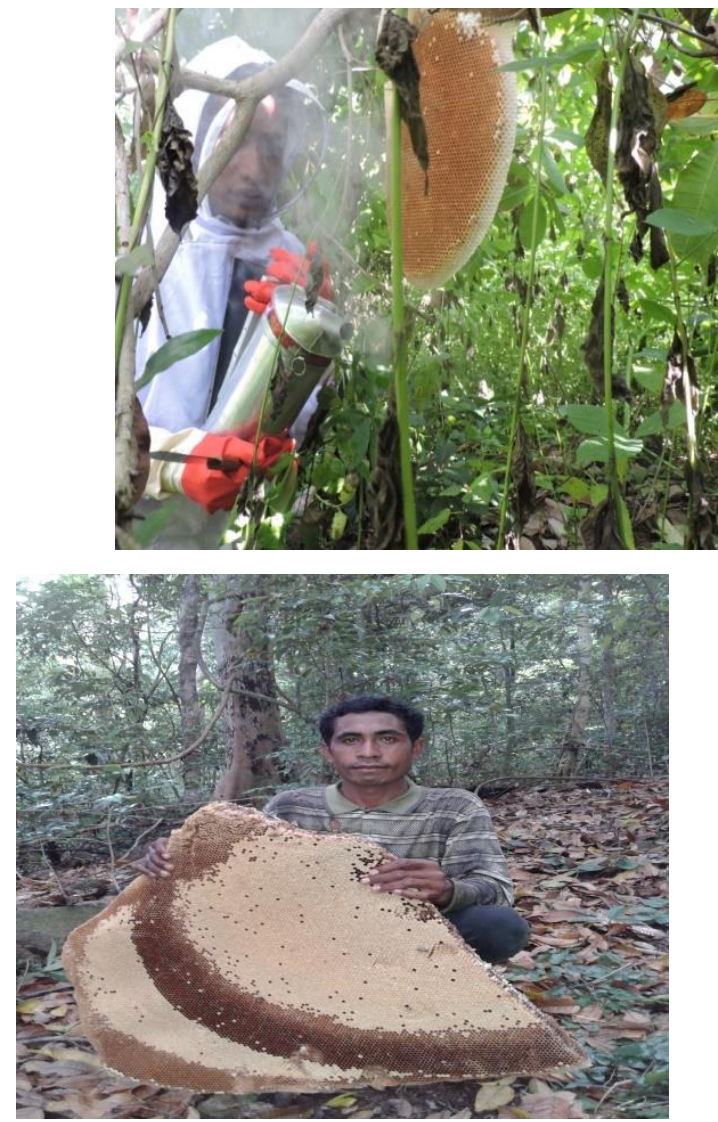

Gambar 1. Aktifitas masyarakat desa Hiay (Wetar) saat pengambilan sarang lebah madu

\section{Pemasaran Madu Wetar}

Marketing mix adalah kombinasi dari kegiatan-kegiatan pemasaran yang dilakukan untuk memasarkan barang dan jasa tertentu selama periode waktu tertentu kepada pasar tertentu. Kegiatan-kegiatan yang dimaksud meliputi keputusan-keputusan tentang 4 variabel yaitu : produk, harga, distribusi dan promosi

1. Produk 
Dalam kaitannya dengan pemasaran, keputusan-keputusan tentang produk mencakup bentuk penawaran secara fsik, merk, pembungkus, garansi dan penawaran purna jual.

Produk madu wetar asal desa Hiay yang selama ini dilakukan oleh masyarakat yakni setelah panen madu ditampung diceregenceregen dan kemudian dibawa ke Ambon disana dikemas dibotol-botol bekas kemudian kemudian dijual ke konsumen. Alur produksi madu wetar terputus - putus hal ini dikarenakan madu wetar merupakan hasil hutan dan bukan dibudidayakan jadi produksinya pun tergantung dari alam (musim) jika pergantian musim secara teratur maka produksi madu wetar akan banyak tetapi jika panas atau hujan berkepanjangan maka hasilnya sedikit bahkan tidak ada sama sekali. Dalam satu tahun biasanya pemanenan dilakukan pada bulan April-Mei dan bulan Oktober-November.Biasanya madu yang sangat baik itu pada bulan OktoberNovember dan putaran musim panen mulai dari desa yang letaknya paling barat hingga ke desa yang paling timur. Madu wetar oleh masyarakat biasanya dijadikan sebagai obatobat tradisional. Selain itu madu wetar memiliki rasa yang disesuaikan dengan nektar (pakan lebah). Dalam satu kali musim panen dapat menghasilkan $10-20$ drum (1 drum $=200$ liter $)$ atau sekitar 2- 4 ton madu .

\section{Harga}

Dari sudut pandang pemasaran, harga merupakan satuan moneter atau ukuran lainnya termasuk barang dan jasa yang ditukar agar memperoleh hak kepemilikan atau penggunaan suatu barang/jasa (Tjiptomo, 1995). Harga madu wetar Rp di desa Hiay berkisar antara Rp 50.000 - Rp 70.000 per botol. Sedangkan ketika dibawa ke kota kecamatan harga berkisar antara $\mathrm{Rp}$ 80.000 - Rp 100.000 per botol. Selanjutnya oleh pedagang besar/pedangang pengumpul dibawa ke Ambon dengan harga Rp 100.000 - Rp 120.000 per botol kemudian diambil oleh pengecer dan dijual dengan harga $\mathrm{Rp}$ 120.000 - Rp 200.000. hal ini dikarenakan sulit dan mahalnya transfortasi dari desa Hiay hingga ke Ambon ibu kota propinsi.

\section{Distribusi}

Madu Wetar dari desa Hiay didistribusikan dengan rantai pemasaran yang panjang hingga sampai ke konsumen dan ini tentunya sangat mempengaruhi harga. Namun karena kualitas dari madu wetar sangat baik walaupun harganya mahal tetapi konsumen sangat berminat untuk membeli madu Wetar asal desa Hiay.Ada 2 bentuk Rantai pemasaran madu wetar asal desa Hiay yakni :

- Kelompok usaha-pedagan besar/pedagang pengumpul - pengecer - konsumen

- Kelompok usaha - pengecer konsumen

4. Promosi

Promosi adalah kegiatan memberitahuan kepada konsumen tentang adanya barang/jasa dengan harga tertentu.Umumnya konsumen mengetahui 
produk madu wetar sudah sejak lama namun karena masih kurang dipasaran dan produksi madu wetar terputus-putus karena sesuai dengan musim maka untuk kegiatan promosi masih dilakukan dari mulut ke mulut.

\section{Faktor-Faktor Yang Mempengaruhi Produksi dan Pemasaran Madu}

1. Peralatan produksi

Adapun peralatan yang digunakan untuk mengambil sarang lebah madu hingga peremasan madu masih sangat sederhana (manual) dan dilakukan berdasarkan kearifan lokal. Dengan demikian sangat beresiko jika seseorang akan mengambil sarang lebah madu yang berada di pohon karena tidak dilengkapi dengan alat pengaman. Sedangkan proses peremasan sarang lebah (pemisahan madu dari sarangnya) masih mengunakan tangan sehingga belum bisa dijamin kebersihannya.

\section{Pengemasan}

Pengemasan suatu produk sangat menarik konsumen untuk dapat membeli suatu produk. Produk madu wetar masih dikemas dalam botol-botol plastik atau botol kaca bekas tanpa diberi lebel tertentu dan tanpa adanya izin dari BPOM maupun Dinas Perindustrian dan Perdagangan. Hal ini tentunya jauh berbeda dengan berbagai produk madu yang ada di pasaran sehingga konsumen terkadang masih mempertimbangkan kemasannya.

3. Alur Transfortasi yang panjang
Maluku merupakan propinsi kepulauan sehingga hal ini berdampak pada akses distribusi suatu barang/produk. Jauhnya jarak (transfortasi) antara dari Desa Hiay ke ilwaki, Tiakur dan kota Ambon yang harus menempuh perjalanan yang lama dengan transfortasi laut sehingga mempengaruhi distribusi dan harga madu wetar dipasaran.

4. Kurangnya promosi : selama ini madu wetar hanya dijadikan ole-ole atau dijual dengan cara barter atau dengan harga yang sangat murah. Promosi yang dilakukan hanya dari mulut ke mulut atau langsung dari pedagang pengecer yang menjual dari rumah ke rumah dan di pasar-pasar tradisional.

5. Banyak produk madu (pesaing) yang beredar dipasaran : madu merk lain yang beredar dipasaran sangat banyak hal ini memberikan dampak tersendiri bagi distribusi madu wetar karena umumnya produk tersebut telah memiliki izin.

Selain itu yang sering terjadi adalah madu sudah tidak murni lagi karena oleh pegadang-pedagang nakal dengan sengaja mencampur madu wetar sehingga menimbulkan image bahwa madu wetar yang dijual oleh pedagang pengecer tidak murni lagi. Namun hal tersebut dapat diminimalisir melalui berbagai promosi tentang bagaimana membedakan madu murni dan yang telah dicampur. 
Upaya Pengembangan Produksi Pemasaran Madu Wetar.

Kelompok usaha madu Wetar di desa Hiay merupakan kelompok yang mengambil sarang-sarang lebah madu hutan dengan tujuan untuk meningkatkan ekonomi keluarga. Kelompok ini terbagi atas 2 dua yakni kelompok usaha Sion 1 merupakan kelompok produksi yang anggotanya berdomisili di desa Hiay pulau Wetar yang bertugas memanen/mengambil sarang lebah madu dari hutan dan melakukankan menyisiran hingga pemerasan madu. Sedangkan kelompok Sion 2 yakni pemasaran yang akan membawa produk madu ini untuk dijual dan bekerjasama dengan komunitas masyarakat yang berasal dari pulau Wetar yang berdominsili di kota Ambon khususnya adalah mahasiswa maupun pemuda-pemudi usia kerja yang sangat menggantungkan hidupnya dari hasil usaha madu. Kelompok Usaha Sion 2 bersama komunitas masyarakat Hiay ini,

mereka mencari pasaran dan menjual madu di kota atau pun saat liburan dan musim panen/panen madu orang-orang ini pulang ke Hiay daerah asal untuk melakukan kegiatan pengambilan madu. Dan jika tidak sempat ke Wetar maka kelompok Usaha Sion 1 maupun kelompok Usaha Sion 2- yang mengirim madu dalam jerigen ke Ambon untuk dijual oleh sebagian anggota kelompok yang ada di kota maupun komunitas masyarakat desa Hiay. Karena jauhnya perjalanan dari Wetar ke kota Ambon dengan menggunakan transportasi laut kapal perintis dengan waktu tempuh 5-7 hari perjalanan maka madu yang dibawa belum dikemas dalam botol-botol yang siap dijual/didistribusikan, melainkan diisi dalam jiregen bekas ukuran 5-10 liter setelah tiba di kota barulah dikemas untuk dijual.

Berdasarkan hasil kajian untuk pengembangan produk madu wetar ini ada beberapa kegiatan yang telah dilakukan sebagai berikut :

1. Sosialisasi dan Penyuluhan: kegiatan sosialisasi dan penyuluhan oleh tim staf pengajar Universitas Pattimura dimaksudkan untuk menambah pengetahuan masyarakat, materi yang disampaikan antara lain:

- Teknik Budidaya Lebah Madu, Strategi Produksi dan Pemasaran Madu, dan cara Pengemasan Produk

2. Pengadaan peralatan utama dan peralatan penunjang panen/produksi dan pemasaran dimaksudkan untuk menunjang kegiatan produksi dan pemasaran. Peralatan utama antara lain :

- Ektrator: berfungsi untuk mengektraksi madu dari sisiransisiran sarang lebah madu, karena selama ini mitra hanya melakukannya dengan teknik pemerasan secara manual

- Smoker: berfungsi untuk pengasapan agar lebah madu keluar dari sisiran sarangnya karena selama ini mitra hanya menggunakan ranting-ranting pohon lalu dibakar untuk mengusir lebah madu dari sisiran sarangnya

- Alat press tutup botol: berfungsi untuk menutup botol kemasan 
dengan cara mengepres/memberikan tekanan pada tutup botol plastik yang digunakan karena selama ini mitra hanya menggunakan botol-botol kemasan bekas.

- Peralatan penunjang seperti: jiregen dan drum penyimpanan sebagai wadah penyimpanan, tali, botol-botol kemasan, sarung tangan dan berbagai peralatan penunjang lainya.
3. Pengujian sampel madu wetar Balai Pengawasan Obat dan Makanan Ambon dimaksud agar madu yang akan dijual memiliki sertifikat hasil yang telah memenuhi standar dan syarat kesehatan untuk dikonsumsi. Adapun hasil uji beberapa parameter untuk kemasan madu ukuran $500 \mathrm{ml}$ adalah sebagai berikut (terlihat pada Tabel.1).

Tabel 1. Tabel Hasil Uji Paramater dari Madu Wetar

\begin{tabular}{|c|c|c|c|}
\hline No & Parameter Uji & Hasil Uji & Satuan \\
\hline 1. & $\begin{array}{r}\text { Pemerian: - Bentuk } \\
\text { - Warna } \\
\text { - Bau }\end{array}$ & $\begin{array}{l}\text {-Cairan kental } \\
\text {-Coklat } \\
\text { - Normal }\end{array}$ & \\
\hline 2. & Angka Lempeng Total & $<1,0 \times 10^{1}$ & Koloni/g \\
\hline 3. & Angka Kapang Khamir & $<1,0 \times 10^{1}$ & Koloni/g \\
\hline 4. & MPN Coliform & $<3$ & $\mathrm{APM} / \mathrm{g}$ \\
\hline 5. & Keasaman & 71,69 & $\mathrm{Ml} \mathrm{NaOH} 1 \mathrm{~N} / \mathrm{Kg}$ \\
\hline 6. & Aktivitas Enzim Diastase & 7,29 & $\mathrm{DN}$ \\
\hline
\end{tabular}

4. Desain kemasan dan level produk madu wetar: dimaksud agar produk madu dapat memiliki label produksi agar lebih mudah untuk dikenal oleh konsumen/masyarakat dan membedakannya dengan produk madu lain yang beredar dipasaran. Madu wetar asal desa Hiay kini dijual dengan merk Sion wetar.

5. Promosi: dilakukan dengan membagikan brosur kepada masyarakat untuk lebih memperkenalkan madu wetar yang beda dari biasanya. Selain itu dengan mengikuti pameran PESONA (Perhutanan Sosial Nasional) untuk memperkenalkan produk madu wetar di masyarakat.

6. Distribusi madu wetar: dilakukan distribusi ke toko-toko, pusat ole-ole maupun supermarket yang ada di kota Ambon.

7. Kegiatan field trip oleh kelompok di pusat-penjualan ole-ole dan supermarket yang menjual madu untuk melihat dan membandingkan berbagai produk madu yang ada dipasaran.

8. Kelompok usaha Madu Sion Wetar dijadikan sebagai kelompok binaan Balai Perhutanan Sosial dan Kemitraan Lingkungan Wilayah Maluku dan Papua untuk kegiatan pengembangan dengan membantu mempromosikan madu wetar saat pameran serta memberikan bantuan peralatan. 

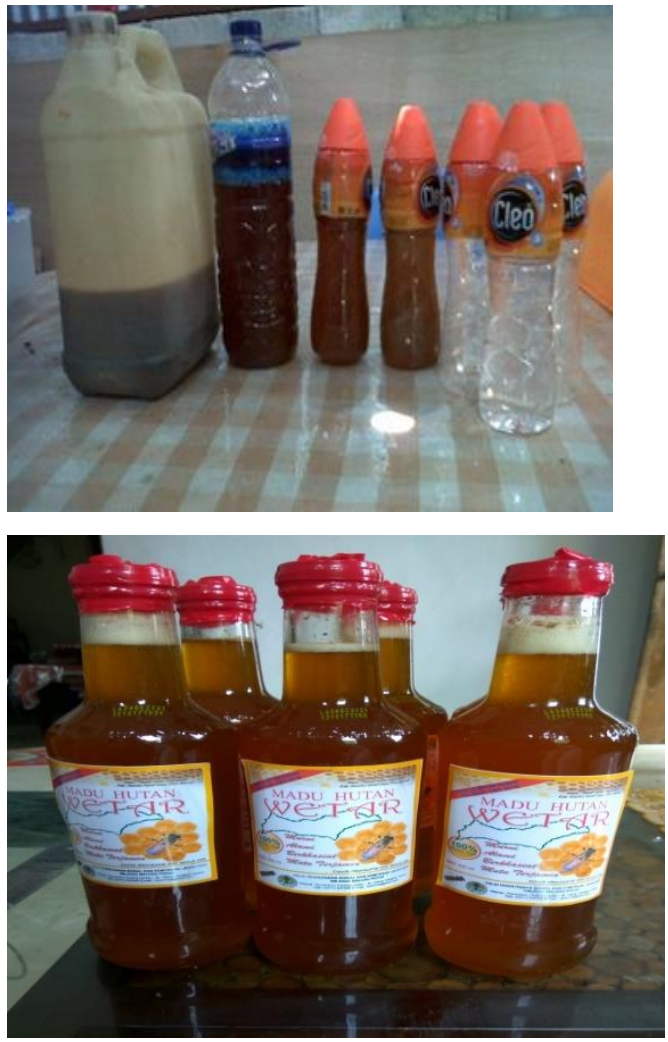

a. Sebelum pengembangan

b. Setelah pengembangan

Gambar 2. Kemasan Madu Wetar Sebelum dan setelah Kegiatan Pengembangan

Dari upaya pengembangan produksi dan pemasaran madu wetar yang dilakukan maka dapat meningkatkan nilai ekonomi madu wetar dimana terjadi kenaikan harga jual yakni Rp 120.000 - Rp 150.000 yang juga berdampak pada peningkatan pendapatan respondepen yakni sebesar $\mathrm{Rp}$ 50.000-Rp 70.000/ $500 \mathrm{ml}$.

\section{KESIMPULAN DAN SARAN}

\section{Kesimpulan}

1. Faktor-faktor yang mempengaruhi produksi dan pemasaran madu wetar asal desa Hiay adalah peralatan produksi yang masih sangat sederhana, pengemasan, alur transportasi yang panjang, kurangnya promosi dan banyaknya produk madu (pesaing)yang beredar di pasaran.

2. Alur produksi madu wetar asal desa Hiay merupakan alur produksi terputus-putus karena disesuaikan dengan musim (alam) sedangkan alur distribusi yakni :

\section{Berdasarkan surat BPOM Ambon Nomor} PM.02.04.1092.04 hasil uji terhadap parameter madu untuk ukuran $500 \mathrm{ml}$ telah lulus uji/memenuhisyarat untuk dikomsumsi.

\section{Saran}

1. Madu hutan merupakan hasil hutan non kayu yang sangat tergantung dari keberadaan ekosistem hutan dengan demikian hutan perlu tetap dijaga.

2. Perlu adanya perhatian instansi terkait dalam pengurusan Izin yang terkadang mendapat kesulitan merupakan suatu hambatan untuk pengembangan usaha kecil. 3. Untuk pengembangan madu wetar perlu dibuat beberapa ukuran kemasan dan disertai dengan hasil uji kandungan/komposisi nilai gizi.

\section{DAFTAR PUSTAKA}

Ambar T, 2004. Kemitraan dan Modelmodel Pemberdayaan, Penerbit Gava Media

Deni Sulaiman. 2013, Keuntungan dan Khasiat Lebah Madu, Penerbit CV Mawar Putra Perdana.

Devyana D. Wulandari, 2017. Kualitas Madu (Keasaman, Kadar Air dan Kadar Gula Pereduksi) Berdasarkan Perbedaan Suhu Penyimpanan. 
Jurnal Kimia Riset Volume 2 No.1.Juli. Prodi D-IV Analisis Kesehatan Fakultas kesehatan Universitas Nadlatul Ulama Surabaya.

Kotler, Philip, 2003, Prinsip-prinsip dalam Pemasaran, Erlangga, Jakarta

Kotler, Philip dan Keller, Kevin Lane, 2009, Manajemen Pemasaran: Edisi 13, Jilid 1, Erlangga Jakarta.

Suparjan dan Hempri Suyatno, 2003. Pengembangan Masyarakat dari Pembangunan sampai Pemberdayaan. Penerbit Aditya Media Yogyakarta.

Swasta B, 2010, Manajemen Penjualan: Pelaksanaan, BPFE, Yogyakarta.

Sudarmaji, 2015. Pembuatan Feature Audio Visual Manfaat Madu Sebagai Pengobatan Herbal Tradional, Jurnal IKON-Prodi-D3 Komunikasi Masa. Politeknik Indonusa Surakarta.

Suherman D, Kadarsih S dan Gusmantoro M.G.2017, Strategi Pemasaran Madu Berdasarkan Karakteristik Konsumen di Kota Bengkulu, Jurnal Sain Peternakan Indonesia Vol. 12 No. 2. April-Juni Jurusan Peternakan, Fakultas Pertanian, Universitas Bengkulu.

Wulandari Devyana Dyah. 2017 Kualitas madu (Keasaman, Kadar Air dan Kadar Gula Pereduksi Berdasarkan Perbedaan Suhu Penyimpanan), Jurnal Kimia Riset Vol. 2 No. 1 Universitas Nahdlatul Ulama Surabaya.

https://ejournal.unib.ac.id/index.php/jspi/arti cle/view/2107 Strategi Pemasaran Madu Berdasarkan Karakteristik Konsumen di Kota Bengkulu. Jurnal Sain Peternakan Indonesia Vol. 12 No 2. 2017. Tanggal akses 11 Agustus 2019 